\title{
UN INTENTO POR EXPLICAR LA VIOLENCIA EN COLOMBIA: ¿Y SI NOS SOMOS NACIÓN?*
}

\author{
Víctor De Currea-Lugo**
}

Hace nueve meses, en un foro en la ciudad de Medellín, con un amigo afirmamos que Colombia no es ni una nación ni un Estado sino una montonera que, cuando avanza, deja muertos. Esto, que podría parecer un chiste de mal gusto de un pesimista desempleado, es la tesis central que intentaré demostrar en los próximos párrafos.

\section{UN POCO DE HISTORIA}

Cuando llegaron los conquistadores al llamado "nuevo mundo" encontraron asentamientos indígenas que poseían culturas más o menos comunes (Perú, México), pueblos que fueron aniquilados por la guerra de conquista y por las epidemias (Argentina, Cuba) y zonas donde, sin estar precisamente despobladas, el desarrollo de los pueblos era local y no trascendían sus fronteras naturales (Colombia).

Además de tal característica, la distribución de los conquistadores en Colombia tampoco fue uniforme (elegían el lugar, acorde con su geografía de origen: andaluces en la costa, extremeños en la montaña, etc.), como lo han sido otros flujos de migrantes que han ido formando verdaderas "repúblicas independientes": en la Guajira predominan los turcos, árabes a lo largo de la Costa Atlántica, las poblaciones negras traídas del Africa crecieron y se mantienen con como el Chocó, el atraso y las condiciones de vida no distan mucho de las de sus antepasados africanos.

Cada uno de los pueblos indígenas "colombianos" también tuvieron un comportamiento particular frente al blanco: una de las leyes de los paeces, al sur del país, les impide mezclar su sangre con la de los blancos; los wayuú cruzan la frontera entre Colombia y Venezuela sin hacer caso al concepto de frontera y constituyen su propia nación. Incluso, algunos pueblos sobreviven en formas primitivas en la selva: los Nukak Makú son un pueblo nómada, de reciente "descubrimiento" y cuya población ha ido muriendo al entrar en contacto con las bacterias y virus de la civilización.

La historia de Colombia ha sido la historia de lo que dejan los otros: el sueño de Bolívar (del que él se ofreció ser el dictador necesario para el progreso), de unir bajo un solo país los territorios de lo que ahora conocemos como Bolivia, predominio en la costa pacífica, al punto que en regiones

Venezuela, Colombia, Perú, Ecuador y Panamá, quedó convertido apenas en la Gran Colombia (sin Bolivia y sin Perú), experimento que, a su vez, se fragmentó en Ecuador, Colombia y Venezuela. Durante el siglo XIX, Colombia tuvo 70 guerras civiles (Valencia, 1993: 67), la gran mayoría obedeciendo a criterios regionales o a procesos separatistas en la discusión capital-provincia, antes que a la idea de consolidación de la nación; estas guerras eran una de las pocas formas de participación política. Al comienzo del siglo XX, el territorio del ahora Panamá organizó un movimiento separatista y logró su objetivo.

La tierra que ahora llamamos Colombia no creció ni se puede entender bajo un solo ideal indígena (Azteca o Inca), tampoco perdió a sus nativos, ni fue una ciudad portuaria la que unificó su desarrollo (Lima, Buenos Aires), sino que creció siempre tratando de unir bajo un solo concepto a regiones que entre ellas no guardaban muchas cosas en común; por ejemplo: las ciudades periféricas son más cercanas a sus países vecinos (Pasto al Ecuador y Cúcuta a Venezuela) que a la capital, y en éstas la moneda vecina es tan común como la moneda nacional.

\section{LAS COLOMBIAS}

Estos fenómenos, en la Colombia de hoy, parecen repetirse -por lo menos- en lo político, en lo cultural y en lo militar. Las dinámicas regionales priman sobre cualquier intento nacional. Esto, per se, no es malo, pues países con distintas naciones, en su interior, han podido sobrevivir y hasta consolidarse; la diferencia es que en el caso colombiano las mismas regiones están desarticuladas en sus provincias, y las provincias en sus municipios. La desintegración nacional no es posible porque el país nunca ha estado articulado. 
En lo político, la desarticulación permite a los caciques políticos adaptarse tanto a los procesos nacionales electorales (elección de senadores y de presidente) como a los regionales (representantes a la cámara) y a los locales (elección popular de alcaldes). Los procesos de descentralización no necesariamente generaron procesos de democratización o de redistribución del poder político, sino que permiten una revalidación de los viejos caciques políticos mediante nuevos mecanismos. Como dice Fernando Guillén (1998: 379): "Por un sistema complejo de herencias y captaciones, las encomiendas derivan en la hacienda y absorben la población mestiza, así como la hacienda engendra al gran comerciante y acoge a la población urbana de la clase media. El gran comerciante, a su turno, se hace industrial desde el gobierno, absorbiendo en su sistema de lealtades a la burocracia manufacturera y a la burocracia de servicios del Estado, intentando ampliar su denominación hasta la base obrera mediante la absorción política del sindicalismo".

En lo cultural, Colombia no logra un quehacer colectivo o elementos de integración nacional, de tal suerte que los regionalismos son determinantes, lo cual no es negativo per se, pero que en nuestro caso se cae en ello sin reconocimiento por el otro: la ciudad contra el campo, el centro contra la provincia, el norte del país contra el sur. Ni siquiera contamos con sistemas de vías o de ferrovías que integren el territorio nacional o que contribuyan a la creación de un mercado nacional, sino que cada población desarrolla economías locales que a veces se integran al mercado mundial (café, banano) sin surtir un mercado nacional, o producciones agrícolas que no dan cuenta de las necesidades del país, al punto que Colombia importa arroz del Ecuador y hasta maíz de los Estados Unidos. Otro ejemplo es el de la territorialidad de San Andrés Islas, en las cuales se necesita ser nativo para tener derecho a la residencia, a la cual no pueden acceder colombianos no san-andresanos.

Ante la ausencia de proyectos nacionales, del principio social de solidaridad y del reconocimiento del otro como persona (aspecto en que la iglesia con su poder sobre el sistema educativo ha contribuido bastante) y la violencia eternizada, sólo quedan los proyectos y las salidas individuales aun por encima del otro.

El Estado mediante la impunidad, el ejercicio sesgado de la justicia, la perversa interpretación de la ley, el silencio frente a ciertos delitos (narcotráfico, paramilitarismo), la corrupción (frente al contrabando y la mala administración de empresas públicas), ha patrocinado y perpetuado formas de relación entre las personas y el Estado mismo, en las cuales el ejercicio de los derechos pierde su carácter legítimo y se convierte en un intercambio de favores.

También los particulares usan los favores como una forma de relación entre personas antes que el ejercicio de derechos: es decir, se produce la clientelización de las micro-relaciones sociales. Las consultas médicas, el pago de servicios públicos, los cupos escolares y universitarios, los créditos bancarios, no transcurren dentro de unas reglas de juego que respeten todos, sino dentro de un mercado de favores y contra-favores que crean verdaderas redes de poder y que determinan la dinámica social. La ausencia o la debilidad del Estado, más una dinámica estatal similar (de favores y contra-favores), hace perpetuo este sistema y "funcional" para los círculos de poder, donde el paradigma no es el ciudadano que ejerce derechos y deberes sino aquel que cuenta con las tretas o artificios necesarios para sobrevivir entre estas redes retorcidas que, a su vez, han retorcido la dinámica colectiva.

En lo militar. Las guerras del siglo XIX fueron "feudales", en el sentido de que obedecían a la dirección de los hacendados de una región (donde eran a la vez jefes políticos y económicos) en contra del centro; guerras que al terminar no dejaron un mapa nacional sino un fragmentado mapa de regiones que se articulan formalmente pero cuya cultura, geografía e historia son diferentes. Las fronteras naturales juegan un papel importante por cuanto la variabilidad biológica de una región a otra determina diferencias en las comidas, el vestuario, los ritmos musicales y las prácticas cotidianas; para muchos, en el siglo XX estamos en la guerra por la definición de un Estado-Nación que ya lograron nuestros vecinos.

En la geografía de la guerra actual, la fragmentación del país no es menos diferente. Aunque los actores armados firmen con la misma sigla, sus dinámicas son, en todo caso, más del orden regional que del nacional. Esto facilita el surgimiento de disidencias o la aparición de grupos con reivindicaciones o desarrollos eminentemente regionales (la guerrilla Partido Revolucionario de los Trabajadores, PRT, en la Costa Atlántica, la guerrilla indígena Quintín Lame -MAQL- en el Cauca, entre otras) y genera diversas percepciones de un mismo actor armado, de una zona a otra, variando así su grado de legitimación entre la población (por sus acciones, por ejemplo) o de rechazo (por su lumpenización). El ELN más que una guerrilla nacional es una federación de grupos armados con grandes diferencias entre ellos.

\section{GUERRILLAS}

En Colombia se optó por la guerra de guerrillas, a diferencia de la gran mayoría de países del continente, mucho antes del triunfo de la revolución cubana; tuvo su origen, no en las ideas marxistas, sino en el enfrentamiento entre los partidos tradicionales liberal-conservador, el cual, durante los años 50 dejó 300.000 muertos. En efecto, las guerrillas colombianas "aprenden de la experiencia conspirativa e insurreccional del bipartidismo y al optar por la subversión contra el orden público interno no hacen otra cosa que esgrimir contra el establecimiento público tradicional en su conjunto, las mismas armas que el liberalismo y el conservatismo habían empleado el uno contra el otro o contra terceras fuerzas a lo largo del siglo XIX y buena parte del siglo XX" (Valencia, 1993: 75).

Estas guerrillas liberales nacidas de la violencia bipartidista en 1949 y, luego, de resistir la ofensiva al mando de asesores norteamericanos en las montañas de Marquetalia en $1964^{\prime}$, pasaron a constituirse, con la anuencia del PC,

1. Para Regis Debray, la autodefensa campesina como forma guerrillera es un fracaso, y la acusa de ser espontaneismo militar siendo preferible un ejército popular diferenciado de las masas, a favor de la teoría foquista. Lo cierto es que las FARC son, hoy día, la guerrilla más vieja del 
en guerrillas comunistas: las FARC². En 1967, por división en el seno del PC, nace el PCC $\mathrm{m}-\mathrm{l}$, que da origen a su propio brazo armado: el Ejército Popular de Liberación -EPLpro-chino. Y en 1974, ex-miembros de la Juventud Comunista y de las FARC forman el M-19. Por su parte, el ELN nace a mediados de los años 60 , teniendo como modelo la guerrilla guevarista. De estas guerrillas sobreviven las FARC, con más de 60 frentes, el ELN y unos pocos frentes del EPL.

Durante los 80, hubo un gran desarrollo en la guerrilla colombiana (el ELN pasó de su casi destrucción a un cuerpo de ejército estable mediante una fuerte reestructuración dirigida por su entonces comandante, el cura Manuel Pérez). Las FARC y el EPL lograron un crecimiento relevante, con formación de nuevos frentes. Las organizaciones guerrilleras colombianas contaban con un apoyo, relativamente importante, entre el campesinado de sus zonas rurales de influencia e incluso de pequeños pueblos que eran ocasionalmente tomados por la guerrilla.

Es curioso que, con la notoria excepción de Manuel Marulanda Vélez, de las FARC, los dirigentes de las guerrillas no sean campesinos ni aún en las guerrillas rurales, sino que muchos sean líderes provenientes del movimiento estudiantil. Para Jorge Castañeda, la lógica de la guerra de guerrillas incluía entregar la conducción a "los hombres supuestamente sólidos de las clases medias, urbanas e ilustradas (que) iluminarían la conciencia de las masas empobrecidas y carentes de ciudadanía” (Castañeda, 1995: 87).

A diferencia de las demás guerrillas latinoamericanas, las FARC nacen de autodefensas campesinas que, a su vez, nacieron en la confrontación entre partidos de derecha; mantienen el control de una parte importante del territorio colombiano, han desarrollado una gran capacidad militar y manejan una temporalidad y un carácter eminentemente rural, lo que quiere decir que sus posiciones en un proceso de paz son diferentes a las temporalidades de los gobiernos cuatrienales y de los industriales e intelectuales urbanos.

A finales de la década pasada y durante la presente, entre las masas que apoyaban la lucha armada surtió efecto la caída del muro de Berlín y el deterioro de las estructuras políticas proclives a la guerrilla (poco existentes) ante el avance de posiciones militaristas dentro de las filas de la insurgencia ${ }^{3}$, lo que ha llevado a una pérdida importante de simpatía en zonas urbanas y de fortalecimiento del discurso paramilitar en zonas de antigua influencia guerrillera.

Algunos hechos relevantes como la masacre de Tacueyó ${ }^{4}$ la "purificación" en las filas de cuatro frentes de las FARC que dejó 100 muertos, y las prácticas verticalistas y militaristas para con la población civil y para con sus propios combatientes, más las prácticas reiteradas de secuestro, la mal llamada "limpieza social" ", la extorsión, el irrespeto por las formas de organización indígena ${ }^{6} \mathrm{y}$ relaciones con el narcotráfico, han desdibujado la guerrilla colombiana, la cual aparece vinculada con "asesinatos políticos, secuestros, utilización de minas 'quiebrapatas' y ataques a objetivos civiles, incluidos autobuses públicos" ’ .

\section{GRUPOS PARAMILITARES}

El fenómeno paramilitar, principal responsable del desplazamiento forzado y de los asesinatos políticos, ha ido creciendo desde comienzos de la década pasada. Uno de sus desertores confesos fue testigo de la colaboración estrecha con los grupos paramilitares de "comandantes militares, narcotraficantes, y líderes paramilitares; entre ellos Pablo Escobar, Gonzalo Rodríguez Gacha, Fidel Castaño ${ }^{8}$ y Víctor Carranza" $"$, nombres asociados con masacres, con la escalada de narcoterrorismo y con asesinatos en las minas de esmeralda. Así, pues, en redes donde han confluido capos del narcotráfico, ganaderos, militares, paramilitares, asesores norteamericanos, esmeralderos y mercenarios, se ha perpetuado, bajo el manto de la impunidad silenciosa y protectora, la guerra sucia en Colombia.

En la región de Urabá, desde 1988, se dieron manifestaciones fuertes de la llamada, en ese entonces, "contrarrevolución de Urabá". Ante el auge de "vacunas y boleteo" (chantaje y extorsión) por parte de los grupos guerrilleros de la zona, los ganaderos decidieron armarse y enfrentar a la guerrilla. En esa dinámica, Urabá se dividió: al norte los paramilitares dirigidos por Fidel Castaño, al sur las guerrillas, y en el medio la población civil. A finales de 1996, la alianza militares-paramilitares dio lo mejores frutos: las guerrillas de las FARC fueron aisladas de la región luego de innumerables masacres a líderes populares y campesinos.

Desde 1994, las Autodefensas Unidas de Colombia, AUC, se han ido desplazando a otros departamentos como Cesar, La Guajira, Santander, el resto de Antioquia y varios puntos del sur del país. Varias poblaciones de estos departamentos han ido quedando vacías al producirse éxodos

mundo. Además, en ese momento la autodefensa no era una “opción” revolucionaria sino la única posibilidad de supervivencia. Ver: DEBRAY, Regis, (1967): ¿Revolución en la revolución? Casa de la Américas, La Habana. pp. 22-23, y PIZARRO LEÓN-GÓmEZ, Eduardo (1989): "Los orígenes del movi miento armado comunista en Colombia: 1949-1966” en Análisis Político núm. 7, 7-31. Bogotá.

2. Las FARC nacieron, como tal, con 350 hombres, con la experiencia militar previa de los movimientos de autodefensa y con el respaldo político del PC. Es decir, con más de la mitad de los hombres con que contaba la Unión Revolucionaria Nacional Guatemalteca -URNG- en el momento de su desmovilización, dato a tener en cuenta para el análisis del actual proceso de paz. Ver: PIZARRO: Los orígenes... Op. cit., p. 30.

3. Ver, para el caso colombiano: PIZARro: Los orígenes... Op. cit., p. 26 .

4. Masacre en la cual un comandante de una disidencia de las FARC bajo la imagen de infiltrados, fusiló a casi 200 de sus hombres. Ver: DE CURREA-Lugo, Víctor, (1997): De la violencia y otras costumbres, pp: 137 142. Bogotá: Signos e Imágenes.

5. COMISIÓN COLOMBIANA DE JURISTAS: Colombia, derechos bumanos y derecho bumanitario: 1995 . Bogotá, 1996, p. 9.

6. La creación del MAQL es la necesidad del movimiento indígena de tener un organización armada ajena a las FARC, con la que no se sentía identificado y con las que habían grandes diferencias por su uso instrumental del movimiento indígena. Ver: PIZARRO LEÓN-GÓMEZ, Eduardo (1991): "Elementos para una sociología de la guerrilla en Colombia" en Análisis Politico núm. 12, p. 10. Bogotá

7. Human Rights Watch / AMÉRICAS, Informe Anual sobre la Situación de los Derechos Humanos en el Mundo. 1997, p. 23.

8. Fidel y Carlos Castaño son los principales comandantes de la organización paramilitar más grande, conocida como Autodefensas Unidas de Colombia, AUC.

9. Human Rights Watch / AmÉRICAS: Las redes de asesinos de Colombia: Militares, paramilitares y Estados Unidos, New York, 1996, p. 20 . 
masivos por el arribo de los paramilitares. Acceder a las ciudades fue una de las conclusiones de la tercera cumbre nacional de autodefensas, lo que ya se observa, por ejemplo, en Medellín.

Las acciones de los paramilitares ${ }^{10}$ se basan en la idea de quitarle el agua al pez" ${ }^{11}$. En 1987, el gobierno colombiano reconoció la existencia de 128 grupos paramilitares ${ }^{12}$, que a mediados de 1997 constituyeron las AUC, actualmente con más de 5.000 hombres. Lo peligroso de este proyecto paramilitar es que produce una clara negación del principio del monopolio de la fuerza por parte del Estado, que conlleva no sólo a la autorización a particulares para ejercer la violencia, sino a la casi nula penalización de esta violencia, aunque produzca consecuencias tan graves como la violación sistemática de derechos fundamentales.

$\mathrm{El}$ aumento de las violaciones de derechos de la población civil atribuidas a los paramilitares, la disminución de las atribuibles a los agentes del Estado y el hecho de que "el número de personas muertas o desaparecidas por razones políticas no ha sufrido variaciones en (un) mismo lapso" ${ }^{13}$, permite presumir una transferencia de funciones, sugerida también por los vínculos entre militares y paramilitares que han sido denunciados por los mismos Estados Unidos y por numerosas ONG's internacionales.

\section{FUERZA PÚBLICA}

En el conflicto armado, el Estado colombiano presenta dos caras: una cara social que se materializa (con graves desigualdades y poquísimos recursos) principalmente en los servicios de salud y educación, y una cara represiva representada en las Fuerzas Militares. Este discurso permite culpabilizar a la Fuerza Pública por sus atropellos pero sin que esto comprometa al resto del Estado, de tal manera que el gobierno puede presentarse en los foros internacionales, donde es cuestionado por la situación de derechos humanos, más como una víctima que como victimario.

En enero de 1994, dos suboficiales de la Armada Nacional se entregaron a la Fiscalía General, revelando la participación de la Red de Inteligencia -con jurisdicción en Barrancabermeja- en más de cien muertes ocurridas durante 1993. Según sus declaraciones, el Jefe de Inteligencia Militar de la Armada habría ordenado la lista de muertes, en la que figuran dirigentes cívicos y sindicales, y activistas de organizaciones políticas de izquierda.

En la región de Trujillo, Valle, según la ONG Justicia y Paz, entre 1989 y 1993 se produjo el asesinato de más de 200 víctimas a manos de militares, por métodos tan atroces como despedazar vivos a los campesinos usando motosierras. Este caso fue investigado en Colombia y los militares involucrados fueron declarados inocentes. El caso, luego, fue presentado ante la Corte Interamericana de Derechos Humanos donde se demostró la culpabilidad de los agentes del Estado, tal como lo reconoció el expresidente Samper. De estos militares, varios han ascendido y la mitad han sido condecorados. Lo peor es que cualquier tipo de denuncia nacional o internacional sobre la alianza entre militares y paramilitares es tildada de ser realizada a expensas de los grupos insurgentes.
Históricamente, los militares juzgados en Colombia por violación de derechos humanos se amparan en figuras como la obediencia debida o se reduce el caso a faltas del servicio. "El mismo oficial que ordenó el asesinato de Irma Vera Peña en 1987, una joven embarazada de 17 años (...), fue el juez instructor del caso, y se absolvió a sí mismo y a sus hombres", según America's Watch. Dice el informe de America's Watch de 1996 sobre Colombia, que "en lugar de castigar a los oficiales de bajo y medio rango que toleraron, planearon, dirigieron y hasta participaron en la violencia paramilitar de los ochenta, se les ha promovido y recompensado, y ahora ocupan los más altos cargos dentro de las Fuerzas Armadas" ${ }^{14}$.

Más grave es que "los militares no sólo no son reconocidos como impunes por los gobiernos democráticos; además se sienten a sí mismos impunes al considerarse apóstoles de la paz y el orden" (Wettsein, 1991: 162). Estas acciones se alimentan de un pensamiento en el cual hay: 1) un orden que proteger y, 2) un enemigo a eliminar por cualquier método (Waldmann, 1995: 21). Esto se materializa en una "combinación de formas de lucha" que incluye los métodos legales (más drásticos mediante el uso de legislaciones de excepción) y acciones clandestinas, amparándose en la invocación permanente de figuras como la seguridad jurídica, la nación o el bienestar general, y permite (lo más grave) su legitimación frente a la sociedad.

Desde 1989, Colombia se ha convertido en el país receptor de la mayor cantidad de ayuda militar por parte de los Estados Unidos. Según Noam Chomsky, hay una relación directa entre la cantidad de ayuda militar brindada a los países latinoamericanos (como El Salvador, Perú y Colombia) y el número de violaciones a los derechos humanos. Chomsky afirma que los Estados Unidos andan tras "el aparato represivo de torturas, desapariciones y asesinatos en Colombia" desde hace más de tres décadas (Chomsky, 1996: 4-7). En 1991, unidades de la Agencia Central de Inteligencia de Estados Unidos (CIA) apoyaron a las fuerzas armadas colombianas para la reestructuración de su aparato militar. En esa modernización "convirtieron a los paramilitares en componente clave de su aparato de inteligencia" ${ }^{15}$.

Ante la acción de militares y paramilitares, la respuesta de las FARC fue más o menos similar: combatir el terror con terror y masacrar a campesinos colaboradores, supuestos o reales, del Ejército. Principalmente, tres prácticas han llevado al deterioro de la imagen de la guerrilla: 1) las masacres a campesinos y otros ataques a la población civil, 2) el secuestro como forma de financiación, y 3) la relación con el narcotráfico; coyuntura muy bien aprovechada por el

10. "PARAMILITAR: Viene a denominar a una organización clandestina de hombres armados, que pueden incluir oficiales militares en servicio (activo) o retirados, que trabaja en colaboración estrecha con las fuerzas de seguridad". Op. cit. HUMAN RIGHTS WATCH / AMÉRICAS: Las redes de... p. 4.

11. Al respecto ver: Medina Gallego, Carlos, (1992): “Paramilitares, autodefensas y narcoterrorismo en Colombia. 1980-1990", en Cuadernos Africa - América Latina, núm. 7, pp. 73-85. Madrid.

12. Wettsein, Germán, (1991): “Los impunes, una minoría peligrosa", en Nueva Sociedad, núm. 111, p. 158. Caracas.

13. Comisión Colombiana de Juristas, (1995): Colombia, Derechos Humanos y Derecho Humanitario, p. 9.

14. Op. cit. HumAN RIGHTS WATCH / AmÉRICAS: Las redes de... p. 6.

15. Op. cit. Human Rights WatCH / AmÉRICAS: Las redes de... p. 6. 
gobierno para ahondar el desprestigio del movimiento armado. Para Medina, "el movimiento insurgente contribuyó con sus políticas de financiación y consecución de recursos económicos a justificar la creación de grupos parainstitucionales (...) pero no son las causas del mismo, sino que éstas deben buscarse en las estrategias oficiales de lucha contrainsurgente" (Medina, 1992: 77).

Según el informe sobre 1996 de la Comisión Colombiana de Juristas, el conflicto armado ha tenido un incremento importante que, además, consume el 21,4 por ciento de los ingresos tributarios del gobierno nacional ${ }^{16}$. Ese aumento de las hostilidades no se asoció con un aumento al cumplimiento de las normas del derecho internacional humanitario.

La violencia política ${ }^{17} \mathrm{es}$, pues, una herramienta usada tanto por la izquierda de América Latina, y usada también como respuesta estatal: la represión mediante el uso legítimo y/o constitucional de la fuerza. Los dos discursos son autoreferenciales: se validan en sí mismos y en la violencia del otro, sin establecer límites, llevando a un peligroso concepto de "nivel de violencia aceptable", en cuanto una violencia -por cruenta que sea- sea un poco inferior a la del otro. Esto genera no sólo la justificación de la violencia, sino que determina, como en muchos casos de la "guerra civil irregular" ${ }^{18}$ que vive Colombia, el apoyo de sectores campesinos optando por el "menos dañino" de los ejércitos enfrentados.

\section{ANTERIORES PROCESOS DE PAZ}

Cuando la guerra, como mecanismo, se desgasta y se entra en una situación de imposibilidad militar de triunfo de una parte sobre la otra (empate negativo), incluso instrumentalmente, la paz es una propuesta "militar". Esta lógica llevó a varios gobiernos y organizaciones armadas a desarrollar negociaciones de paz, leyes de amnistía y/o indultos y procesos de reinserción guerrillera en Colombia (M-19, EPL, MAQL, el PRT)

Los procesos tuvieron reveses, se desarrollaron en medio de las acciones hostiles, al punto que se hacía la guerra con más intensidad para llegar con más peso a la mesa de negociación ${ }^{19}$. En Colombia hubo dos procesos de paz: uno, a mediados de los 80, con el EPL y el M-19 que regresaron a la lucha armada tras la muerte de varios de sus comandantes en manos de agentes del Estado, y con las FARC que dieron origen a un frente político amplio (la UP), hoy por hoy desmantelado después del asesinato de 2.500 dirigentes regionales; y dos, otro proceso a comienzos de los 90 , con la desmovilización y entrega de armas del M-19, la división en las filas del EPL (un sector minoritario continúa en armas) y la reinserción de grupos de reciente origen como el PRT, el MAQL y una escisión minoritaria del ELN: la Corriente de Renovación Socialista, CRS. En estos procesos de paz, los comandantes de las guerrillas evidenciaron las mismas ambiciones personalistas con las que dirigieron las guerrillas. Los comandantes ocuparon cargos que van desde el parlamento hasta direcciones de institutos descentralizados, mientras los combatientes rasos, sin empleo, buscaron suerte, probando desde ventas callejeras hasta asaltos bancarios.
Entre marzo de 1990 y junio de 1994 se produjo la reinserción nada despreciable de 5.470 guerrilleros y milicianos (Moncada, 1996, 85), los que, una vez desarmados, no contaron con mecanismos de incorporación social y permanecieron excluidos. Hoy podrían continuar en lucha unos 15.000 guerrilleros de las FARC y unos 7.000 del ELN, para un total de 22.000 hombres en armas.

$\mathrm{El}$ asesinato de cientos de ex-guerrilleros y el bloqueo político a los partidos o movimientos políticos que fundaron los reinsertados ha sido tan grande, que la historia parece darle la razón a los que siguieron en la lucha armada y convencidos de que la paz era un fracaso. El asesinato de comandantes parece enseñar, históricamente, que una vez que se opta por la guerra muy difícilmente se vuelve a la paz, por lo menos entendiendo la paz como armisticio. Guadalupe Salcedo (guerrillas liberales), Carlos Pizarro (M-19), Oscar William Calvo y Ernesto Rojas (EPL) son algunos de los comandantes guerrilleros asesinados una vez firmaron la paz con los gobiernos. Es decir, Colombia ha quemado fórmulas y etapas de procesos que en otros países sí han permitido tránsitos hacia la paz y el armisticio.

El M-19 tuvo dos opciones de ser gobierno: el Ministerio de Salud y la Asamblea Nacional Constituyente. En el primero actuaron como en gueto (la teoría foquista llevada a la burocracia), sin que hicieran una gestión ejemplar, pasando más con pena que con gloria: en su paso por este Ministerio, reprodujo los mismos vicios de sus antecesores: corrupción y clientelismo. En la Asamblea Nacional Constituyente, donde lograron 19 escaños de 80, dieron sus puestos -en uno de los actos más irresponsables que ha hecho la izquierda en Colombia- a representantes de la derecha, a la hija de un poeta, a un paramilitar y hasta al entrenador de la selección nacional de fútbol, todo en aras de la "unidad nacional".

La Unión Patriótica (UP) es un caso alarmante: el intento de un grupo guerrillero (las FARC) por tener un partido político amplio, con miras a la participación electoral, terminó en un genocidio a lo largo de muchos años. Esto, más las numerosas muertes de reinsertados del EPL y la encerrona a la CRS (entre asesinatos y bloqueos que impiden su real participación electoral), muestran que la vía electoral no seduce fácilmente a las guerrillas colombianas.

La criminalización de la protesta popular es tan vieja como la guerra de guerrillas (Pizarro, 1989: 24) y la opción

16. HeRnández, Isidro, (1996): “La Bonanza de la Guerra”, en Revista Cien dias vistos por Cinep. Vol. 8 No. 34, p. 12. Citado por la Comisión Colombiana de JuRistas. En: Op. cit. Colombia, Derechos Humanos y Derecho Humanitario: 1996, p. 55.

17. "Se entenderá como violencia política aquella ejercida como medio de lucha político-social, ya sea con el fin de mantener, de modificar, de sustituir o de destruir un modelo de Estado o de sociedad, o también de destruir o de reprimir a un grupo humano con identidad dentro de la sociedad por su afinidad social, política, gremial, étnica, racial, religiosa, cultural o ideológica, esté o no organizado". En: CINEP y Justicia y Paz: Panorama de derechos bumanos y violencia politica en Colombia: Noche y Niebla. Núm. 1, Bogotá, 1996, p. 6.

18. La categoría de "guerra civil irregular" ha sido usada de manera frecuente en conferencias y análisis políticos por académicos colombianos como Eduardo Pizarro, Alejandro Reyes y Hernando Valencia.

19. Las mayores ofensivas de la guerrilla en Colombia, durante la presente década, se han producido días previos a eventuales conversaciones de paz con el gobierno, tanto en las llevadas a cabo en Caracas (Venezuela) como en Tlaxcala (México) 
militar tan vieja como el intento de nación. Eduardo Pizarro habla de la "insurgencia crónica" perpetuada en el paisaje político (Pizarro, 1991: 8) que sumada a una rápida militarización de la izquierda llevó a una frágil izquierda urbana legal; y sumando a esto los mecanismos antidemocráticos del Estado (criminalización de la protesta social), se explica la inexistencia de una oposición de izquierda legal (ilegalización del PC en los 60, exterminio de la UP).

Uno de los problemas, de hecho, que tiene el conflicto armado es el reconocimiento de los involucrados, tanto por ellos mismos como por sus enemigos. Por ejemplo, las Autodefensas firman sus comunicados como "organización civil armada", el ELN dice ser algo así como el "brazo armado de la sociedad civil” y el General Tapias afirmaba que la Fuerza Pública no era parte del conflicto armado. Entonces, ¿quién hace la guerra en Colombia?

Este juego de palabras más que un problema semántico es una forma para: 1) evadir el cumplimiento de las normas del derecho internacional humanitario, 2) presentar al Estado colombiano como víctima del conflicto antes que como una de sus causas, 3) para cerrar caminos o salidas políticas al conflicto armado.

Los anteriores procesos de paz fueron incapaces de producir consensos nacionales. Tal vez el mejor intento fue en 1991, con la formulación de una nueva Constitución Política que, en la práctica, no ha logrado materializar las libertades y garantías sociales en ella proclamadas, a tal punto que su peso real en la vida de las personas y en el ejercicio de derechos es mínimo.

\section{NARCOTRÁFICO}

La economía colombiana se ha mantenido, a diferencia de la de otros países de América Latina, gracias a las llamadas bonanzas: en los años 70 el ingreso de dólares provenientes del comercio ilegal de marihuana, en los 80 de cocaína y, ahora, en los 90 con la heroína, Colombia ha ido alimentando su economía y presentando niveles de estabilidad. Colombia ha ocupado el primer lugar en la producción de marihuana (en los 70), de cocaína (en los 80) y, ahora, un tercer lugar en la producción de heroína. La producción y comercio de drogas ilegales equivale, en divisas, al 30\% de las exportaciones legales del país ${ }^{20}$.

Estas bonanzas han representado, además de dólares, graves problemas al sistema productivo: la adquisición dic dinero fácil (poca inversión y alta rentabilidad) en un proceso de producción sencillo (es más fácil producir cocaína que azúcar) ha llevado y/o contribuido a una proceso de: 1) sustitución de cultivos lícitos de baja rentabilidad por cultivo ilícitos, 2) desindustrialización del país, (la participación de los sectores agrícola e industrial en el PIB ha descendido en los últimos 20 años sin que se haya diversificado la estructura productiva ${ }^{21}$ ), y 3 ) formación de carteles que desarrollaron prácticas de "justicia privada” y enseñaron a la sociedad a ganar dinero fácil (sicariato, "mulas", etc.), sociedad que a su vez fue cómplice con el fenómeno del narcotráfico.

La economía saltó de la minería a los cultivos legales e ilegales, sin reparar en la posibilidad de la industrialización.
El costo de la propiedad raíz en ciudades como Cali y Medellín estuvieron determinadas por el flujo de dinero proveniente del narcotráfico, mientras en las áreas rurales, bastaría la redistribución de las tierras en manos del narcotráfico (7 millones de hectáreas, aproximadamente) para lograr la reforma agraria. Los narcotraficantes hicieron también presencia en sectores urbanos, con tácticas que van desde la construcción de barrios enteros (Armenia) hasta el reclutamiento de jóvenes pobres para sus ejércitos privados (Medellín).

Ellos lograron no sólo el desarrollo de un mercado y una red necesaria para la producción, procesamiento y distribución de drogas ilegales, sino también un poder tal dentro de la llamada clase política que les permite la manipulación de funcionarios, la presión a autoridades judiciales, la complicidad de sectores de la Fuerza Pública, la compra de adeptos a leyes favorables a ellos en el parlamento y, en general, el poder decidir desde los equipos de fútbol hasta las elecciones presidenciales al financiar los unos y los otros. La financiación de campañas políticas con dineros provenientes del narcotráfico representó corrupción, descrédito, ingobernabilidad, entre otras consecuencias que deslegitiman aun más el sistema electoral.

El narcotráfico es una institución de tal magnitud gracias al poder que deriva de su mercado ilícito, al manejo clientelar y corrupto de las relaciones Estado-personas, a las alianzas hechas en varias regiones con poderes locales (guerrillas, paramilitares, autoridades civiles), y a la impunidad reinante. Tanto ha sido la injerencia de las drogas ilegales en Colombia que le valió el apelativo de "narcodemocracia". Desde julio de 1994, se han ido desenmarañando un subterráneo tejido que comunica políticos, periodistas, militares, reinas de belleza, abogados, artistas y deportistas, con carteles de la droga. La sociedad, a su vez, "aprendió" el consumo suntuario y el sicariato como forma de justicia privada; los más importantes narcotraficantes pertenecieron a la llamada "clase política” (Carlos Ledher, el mismo Escobar), y el colombiano más recordado en varias partes del exterior es, todavía, Pablo Escobar Gaviria.

\section{DERECHOS HUMANOS EN COLOMBIA (Y D.I.H.)}

La Constitución reconoce una gran gama de derechos fundamentales que cobijan a los habitantes del territorio colombiano, lo que es la mayor positivación de derechos en la historia del país. Así mismo, de cara al conflicto armado, la Constitución fija la obligatoria vigencia de las normas del derecho internacional humanitario, DIH. Los grupos de insurgentes han reiterado su compromiso con el DIH y han incluido en sus procesos dichas normas (el ELN, como primer punto en la Convención Nacional que proponen, y las FARC en el punto noveno de la agenda de negociación con el gobierno y los paramilitares o Autodefensas en múltiples comunicados)

20. "Caracterización de la sociedad colombiana" (1997), en Análisis Político, edición especial, p. 26. Bogotá

21. Op. Cit., p. 23 
A pesar de lo anterior, Colombia presenta una curva ascendente de homicidios ${ }^{22}$, violencia política, impunidad, secuestros $^{23}$, ejecuciones extrajudiciales, desapariciones forzadas $^{24}$, y torturas ${ }^{25}$, que hacen del país uno de los más violentos del mundo. En el año de 1993, por ejemplo, el diez por ciento de los asesinatos del mundo se cometieron en Colombia ${ }^{26}$.

Entre octubre de 1994 y septiembre de 1995, de 3.681 muertes ocasionadas por el conflicto armado, sólo alrededor del 40 por ciento ocurrieron en combate ${ }^{27}$. En 1996, según estadísticas presentadas ante las Naciones Unidas por 68 ONG's, de cada diez muertos diarios fallecidos por razones políticas, seis son ejecutados y sólo tres fallecen en acciones bélicas ${ }^{28}$.

Según Amnistía Internacional, en su informe mundial de 1997, "las fuerzas de seguridad y los grupos paramilitares que operaban con su apoyo o con su consentimiento ejecutaron extrajudicialmente a más de un millar de civiles" ${ }^{29}$. Ya en el informe de Amnistía Internacional de 1994, sobre Colombia $^{30}$, se señaló que por razones políticas entre 1986 y 1994, 20 mil colombianos perdieron la vida, por masacres contra indígenas, "limpieza social" contra indigentes, asesinatos de jóvenes en las zonas marginadas de las grandes ciudades, desapariciones forzadas, detenciones arbitrarias, y acciones de terrorismo. En 1992 hubo 502 homicidios en operaciones de "limpieza social"; entre 1978 y 1992 se produjeron 1.500 desaparecidos ${ }^{31}$.

\section{PROCESO DE PAZ ACTUAL}

Llegados a un empate negativo o infinito ${ }^{32}$, los actores armados optan por la negociación, aunque con diferentes intereses: el gobierno entra en el proceso, entre otras cosas, como espacio para buscar legitimidad y aplicar, con más fuerza, las políticas neoliberales (estabilización macroeconómica y ajuste estructural en lo económico, y modernización del aparato estatal en lo político); el ELN llega al proceso planteando una Convención Nacional donde participen diferentes sectores de la llamada "sociedad civil", es decir: buscando un respiro político; y las FARC llegan con un gran peso militar que busca, en la zona despejada por el ejército ${ }^{33}$, consolidar su propuesta militar para luego saltar a un escalón más complejo de la guerra.

El gobierno ha priorizado la negociación con las FARC, otorgándole ventajas y un reconocimiento político con espacio propio (la zona de distensión), mientras el ELN no ha tenido, de parte del gobierno, un reconocimiento del mismo tono, lo que ha empujado a este grupo a la realización de acciones de presión afectando población civil (secuestro de una aeronave en Bucaramanga, secuestro de feligreses en una iglesia en Cali y de pasajeros de embarcaciones sobre el río Magdalena).

Las partes no llegan ingenuas al proceso, traen las frustraciones de los diálogos de Caracas (Venezuela) y de Tlaxcala (México), los recuerdos de la suerte que corrieron los guerrilleros reinsertados de otros procesos, un poder militar probado por parte de las guerrillas. El Estado, sin un plan de negociación claro, da bandazos que generan roces en círculos militaristas (como fue la renuncia de numerosos generales y coroneles por la actitud del presidente en contra del ya exministro de Defensa Lloreda). Este proceso, más que partir de cero, parte de números negativos y las posibilidades de avanzar, a corto plazo, se ven muy difíciles. Otro elemento central, un as sobre la mesa de la extrema derecha, es la presión de los paramilitares quienes, además, están cercando la zona de despeje otorgada a las FARC, erigiéndose como veedores armados del proceso. Los paramilitares buscan, también, un reconocimiento político y por eso han planteado su propia "Convención Nacional".

Luego del comienzo de los diálogos FARC-Estado, los grupos paramilitares asesinaron a casi 140 personas en tan sólo 4 días. Los paramilitares dijeron que los muertos eran simplemente "guerrilleros de civil". Las FARC, por boca de uno de sus comandantes, amenazaron con secuestrar políticos para presionar leyes a favor de los presos políticos. En esas tres posturas: el cinismo, el silencio y la barbarie, están las esperanzas de paz de los colombianos.

La sociedad civil. Los procesos de democratización en América Latina y la crisis de la izquierda han puesto sobre la mesa el concepto "sociedad civil". En el caso colombiano, el concepto ha logrado desplazar al de "población civil" (propia del Derecho Internacional Humanitario) y ganar un puesto en la formulación de acuerdos con los actores armados en la búsqueda de la humanización de la guerra (Acuerdo de Puerta del Cielo, con el ELN y el del Nudo del Paramillo con las AUC).

Esa misma "sociedad civil", sin embargo, no incorpora a todos los elementos articulados y organizados de la sociedad (ONG's, organizaciones de derechos humanos, sindicatos, asociaciones campesinas, etc.) y mucho menos representa a la población en general, sino que está integrada por representantes de los industriales, intelectuales de izquierda, miembros del congreso (senadores), y funcionarios del Estado de alto nivel (Procurador, Defensor del Pueblo)

22. Ochenta y siete homicidios cada 24 horas. El Tiempo (19 de Mayo de 1998): "Impunidad: La gente tiene hoy la palabra”, p. 6A. Bogotá.

23. En 1996 se produjeron 1528 secuestros; en 1997 hubo 1693, y en el primer semestre de 1998, 806. Esto da un total de 4.244 secuestros en dos años y medio. El Tiempo (14 de Julio de 1998): "Estadísticas generales del secuestro 1996-1998”, p. 4A. Bogotá.

24. En 1996 se registraron 134 desapariciones y en 1997, 356 Defensoría del Pueblo (1998): Derechos Humanos para vivir en paz. Quinto Informe del Defensor del Pueblo al Congreso, p. 31. Bogotá.

25. AMnistía InTERnACIONAL, Crónicas del Terror y de la Dignidad. Informe 1997, p. 145. Madrid: EDAI.

26. Organización Mundial de la Salud. Citado por Valencia Villa, Hernando, (1996), en Revista Viejo Topo N. 94, p.50-53. Madrid.

27. Comisión Colombiana de JuRISTAS (1996): Colombia, Derecho Humanos y Derecho Humanitario: 1995, Serie: informes anuales, p. 3. Bogotá.

28. Organización de Naciones Unidas, Consejo Económico y Social. E/CN.4 1996/ NGO /44. abril 9 de 1.996

29. Amnistía InTERnaCional, Op. cit. Crónicas del Terror... p. 144

30. Aministía Internacional, (1994): Violencia Política en Colombia: Mito y realidad. Madrid: EDAI

31. Op. cit.

32. El empate negativo no implica empate militar sino imposibilidad de una fuerza de derrotar militarmente a la otra. VALENCIA, Op. cit. La justicia de... p. 81. Al respecto ver además: PIZARRo, Op. Cit. Elementos para una..., p. 7 . 
La noción que predomina en las calles colombianas es que, más allá de la buena o mala intención de estas personas, lejos de ser voceros autorizados, son representantes de intereses definidos -algunos sólo se representan a sí mismosy no han logrado aglutinar más sectores a su alrededor. Es decir, el espacio denominado de la sociedad civil, repite los mismos vicios heredados de la clase política: exclusión y ausencia de propuestas generales.

Los acuerdos firmados no han sido cumplidos, los voceros de la llamada sociedad civil no tienen participación en las negociaciones entre las FARC y el gobierno nacional, son llamados más para apagar incendios que para tener un puesto definido en el proceso de paz y se han ido desdibujando para quedar de rehenes o de razoneros de los actores armados.

\section{VIOLENCIA COMO RESOLUCIÓN DE CON- FLICTOS}

El problema de la violencia en Colombia es que no está reducida a los actores de la guerra sino que trasciende a toda la población como mecanismo de resolución de conflictos y de interacción social. Sólo el 15 por ciento de los crímenes corresponden al conflicto guerrilla-fuerzas armadas-paramilitares, y el resto son homicidios ocurridos entre particulares.

Es decir, el mayor número de muertos son producidos por civiles. Sólo en la ciudad de Medellín, de 1985 a 1990, se pasó de 5 a 15 asesinatos al día, siendo su mayoría no asociados con el conflicto armado. El Reporte entregado por Medicina Legal ${ }^{34}$ muestra que, de 45.126 autopsias practicadas, el 70 por ciento fue por homicidio.

Informes de Medicina Legal, de 1996 ${ }^{35}$, muestran que durante el primer semestre de 1995, la mitad de las lesiones no fatales en violencia común se produjeron en riñas y atracos (no en acciones de guerra), y en el contexto nacional la violencia común registró un incremento del 13,2 por ciento, con relación al año inmediatamente anterior. En el 32,1 por ciento de las veces el lesionado y el agresor vivían en el mismo domicilio. Esto nos permite afirmar que una de cada tres lesiones personales no fatales ocurren en el mismo espacio de convivencia entre agredido y agresor. Sólo el 2,7 por ciento de las víctimas no tenían formación académica, es decir: no es precisamente el analfabetismo la causa de la violencia.

En Colombia, según el Ministerio de Salud y según un estudio del Banco Mundial ${ }^{36}$, se produce una muerte violenta aproximadamente cada 20 minutos. En los reportes de violencia intrafamiliar, en el 85 por ciento de los casos la víctima es mujer, y en los dictámenes por maltrato conyugal, el 95 por ciento es contra ellas, estando entre los 25 y los 34 años el 50 por ciento de las lesionadas.

Otras estadísticas ${ }^{37}$ muestran datos preocupantes sobre violencia sexual -especialmente contra menores de edad-, maltrato conyugal -predominantemente contra las mujeres- y maltrato infantil -la mayoría de las veces causado por los mismo padres-. El 34.7 por ciento de las víctimas de delitos sexuales están en el grupo entre los 10 y los 14 años. De
4.514 reconocimientos de niños víctimas de maltrato infantil, el 47.7 por ciento de los casos el padre fue el causante de las lesiones. La violación fue el 58 por ciento de los casos entre 5 y 14 años, y el 20 por ciento de los casos entre 1 y 4 años; de las víctimas de delitos sexuales menores de 14 años el 74.2 por ciento de los casos el agresor era conocido de la víctima.

Hace tres décadas, la violencia como causa de muerte en Colombia, ocupaba el noveno lugar; en los años 70 pasó al cuarto lugar y actualmente ocupa el primer lugar (Franco, 1997: 94). Según datos del Ministerio de Salud, de 1987 a 1994, la tasa de homicidios aumentó de 36 a 127 por cada 100.000 habitantes ${ }^{38}$. Como dice Lyotard: "vivimos en una sociedad cargada de demasiados crímenes como para hablar de causas justas".

Para resumir, la sociedad causa seis veces más muertos que la guerra, gran cantidad de lesiones personales no fatales, delitos sexuales contra conocidos; acciones en las que el nivel educativo o la convivencia con los agredidos no son factores que disminuyan los ataques. Las últimas generaciones de colombianos han crecido entendiendo que la justicia por mano propia no sólo es normal sino necesaria, al punto que la ejercen cotidianamente amparados en un Estado incapaz de ejercer justicia. Colombia es uno de los países con más postgrados y estudios de derechos humanos, sin que esa práctica necesariamente afecte la de las relaciones sociales; así como uno de los que más literatura produce sobre la guerra y sobre la paz.

\section{PARA FINALIZAR Y TRATAR DE CONCLUIR}

Colombia es el país del continente con mayor número de procesos electorales, la "democracia" más antigua y estable de la región, dato que es cierto si miramos el número de eventos electorales, la cantidad de candidatos, el circuito nacimiento-auge-muerte de alternativas políticas, las formas de reconocimiento e inclusión de las minorías en los órganos de representación popular, y la validez jurídica de los derechos humanos y de libertades en la Constitución Política.

Pero, muy a pesar de lo anterior, la permanencia de castas políticas regionales y su peso en las decisiones de los mandatarios es una constante, como lo es la violación sistemática a los derechos humanos por parte de los agentes del Estado, las infracciones a las normas del derecho internacional humanitario por parte del ejército, la insurgencia y los grupos paramilitares o de autodefensa.

33. El gobierno del presidente Pastrana despejó de tropas de la Fuerza Pública 42.000 kilómetros cuadrados (un territorio más grande que Suiza) para que las FARC pudieran allí establecer sus mesas de negociación con el gobierno.

34. Subdirección de SERVICIOS ForEnSES, InSTITUTO NACIONAL DE Medicina Legal y CiEnCIAS Forenses: Reporte del Comportamiento de las lesiones fatales y no fatales en Colombia 1994. Santafé de Bogotá: 1995

35. SubdirECCIÓN DE SERVICIOS ForENSES, INSTITUTO NACIONAL DE Medicina Legal y Ciencias FORENSES: Boletín del Centro de Referencia Nacional sobre violencia, Nov. 1995.

36. Una muerte violenta cada 20,5 minutos. Periódico El Espectador, (17 de Mayo de 1996), p. 3A.

37. Subdirección de Servicios Forenses: Op. cit. Reporte del...

38. SubdirECCIÓN DE SERVICIOS FORENSES: Op. cit. Reporte del.. 
Pero lo más grave es la histórica imposibilidad de desarrollar oposición política legal. Varios son las causas de esta dinámica: uno, el dominio de los partidos tradicionales (liberal y conservador), partidos que se precian de ser los más antiguos y estables de la región, y que se han turnado desde el gobierno hasta las guerras civiles, guerras en las que sólo una vez ganaron los rebeldes (Valencia, 1993). Este predominio, sumado a la nula diferenciación programática entre liberales y conservadores hace que podamos hablar de un partido único liberal-conservador que domina el espectro político; dos, la imposibilidad de ejercer la oposición. Durante el periodo comprendido entre 1958 y 1974, los partidos acordaron dividirse por igual el número de puestos en el Congreso y rotarse la Presidencia del país en un pacto conocido como el "Frente Nacional". Este mecanismo, por supuesto, bloqueaba cualquier intento extra bipartidismo de acceder al poder. Esto sumado a las formas más brutales de persecución de opciones políticas de izquierda hizo imposible el ejercicio de la oposición. "La represión a la izquierda colombiana y la magnitud de sus pérdidas no tienen parangón en la historia moderna de América Latina" (Castañeda, 1995: 137), por eso, entre otras cosas, no era necesario un golpe militar pues el poder civil podría ser tan o más brutal que el poder militar y además mostraba la imagen de democracia necesaria para evitar presiones internacionales por la situación política interna que esto generara; y tres, la incapacidad de la izquierda de convertirse en alternativa. Los viejos modelos de acción transplantados mecánicamente de Europa oriental se encargaron del resto, el dogmatismo político convertido en religión, le impidió a la izquierda generar propuestas políticas acordes con la realidad del país. Si bien es cierto que en la década presente ha existido un auge de nuevas organizaciones y candidatos diferentes a los de los partidos tradicionales (incluyendo expresiones de minorías reconocidas por la Constitución), la estructura de poder se mantiene.

El Estado naufraga por varias causas, entre ellas por: uno, una escasa legitimidad, pues la sociedad no reconoce en él ni una posibilidad de justicia, ni el monopolio de la fuerza, ni una alternativa que posibilite la convivencia democrática; dos, un bajo control territorial: el Alto Comisionado para la Paz, reconocía que por lo menos 130 de los algo más de 1000 municipios colombianos están en manos de la insurgencia, dato que, además, se queda corto con la realidad (sin contar aquellos en manos de los paramilitares, el contrabando, los grupos de esmeralderos, el narcotráfico, etc.); y tres, la incapacidad para aplicar las leyes, lo que, además, deriva en el ejercicio de la justicia por mano propia.

El concepto de nación no sobrevive fácilmente si revisamos: uno, la gran variabilidad cultural que no logra articularse en propuestas que trasciendan el ámbito de lo local; dos, la ausencia de propuestas nacionales y de contrato social; tres, la primacía de la identificación con las regiones antes que con el país (se es primero antioqueño que colombiano, por ejemplo).

Como mencionábamos al comienzo, la división de territorios para dar origen a Colombia es fundamental para entender lo que ahora es, y lo que podría ser su futuro. En 1998, el ELN propuso la federalización del país como una forma de buscar la reconciliación nacional, las AUC levantaron entonces, como una de sus principales banderas, la unidad nacional. Pero más allá del protagonismo político lo que se observa sí es una real federalización (no reconocida) del territorio entre los actores armados.

En Colombia la guerra no es la continuación de la política por otros medios sino su protección: los actores armados son la posibilidad del ejercicio de la política (política militarizada) por su respaldo de fuerza, su control territorial y sus formas de presión al contrario.

Hemos mostrado una serie de características de Colombia que nos permiten ratificar la idea de la inexistencia de Estado-nación colombiano. Así como en los barrios populares en desarrollo, la solidaridad es necesaria para la supervivencia o el caos se apodera de la vida (en los barrios estables y de mejor nivel las personas pueden prescindir de su vecino). En otros países que tampoco pueden exhibir una nacionalidad definida, la situación político social es diferente y, por tanto, esa carencia no es una debilidad, para nosotros esa carencia significa no tener precisamente una de las opciones para salir de la crisis (y sin otras opciones a la vista).

Nuestro inicio no contó con comunidades indígenas fuertes, el proceso de conquista y desarrollo colonial fue dispar de una región a otra, desarrollándose culturas propias locales (ropa, comida, música, etc.). Esta sensación de pequeñas naciones es tal que el Putumayo (una región casi selvática) tiene un pequeño grupo guerrillero separatista, y otros grupos como el ERP y el "Jaime Batemán Cayón" han permanecido en sus territorios (Bolívar y norte del Cauca, respectivamente) sin trascender a una presencia nacional. Las autodefensas todavía no han logrado tener un mando real sobre sus diferentes grupos, que permanecen autónomos bajo la orientación propia del "hacendado" regional. En la guerra actual, el nivel discursivo de la mayoría de combatientes rasos es tal, que fácilmente cambian de grupo, incluso hacia grupos enemigos, a cambio de un mejor sueldo, lo que los hace "vividores" de la guerra antes que portadores de propuestas políticas.

Otras violencias regionales tienen dinámicas propias: la zona de Boyacá libró la guerra de los grupos esmeralderos mediante dinámicas locales que no comprometían otras regiones y cuyas salidas se concertaron en lo local; las milicias y otros grupos de jóvenes armados de Medellín, cuyo número es de varios miles, desarrollan formas de poder en sus barriadas y determinan la de los barrios mediante controles que no sobrepasan esas fronteras, e incluso con actitudes mercenarias "trabajan" ocasionalmente al servicio del paramilitarismo ${ }^{39}$; el control social ejercido por los contrabandistas en el departamento de La Guajira se desarrolla como otra micro-nación, cuyo comercio no tiene ningún tipo de control por la autoridades centrales. Estos tres ejemplos ilustran la ausencia del concepto Estado-Nación, a los cuales podríamos agregar las particulares dinámicas de las zonas rurales en las que se cultiva coca, donde el poder político y el control militar está determinado por los carteles a veces

39. Por ejemplo, para el secuestro de los trabajadores de derechos humanos del Instituto Popular de Capacitación, IPC, y para el de la senadora Piedad Córdoba. 
en asociación con la guerrilla, a veces en asociación con paramilitares y otras con las autoridades locales. Violencias y controles sociales todos diferentes, pero todos amparados ( $\mathrm{y}$ alimentados) en la inexistencia del Estado-Nación.

No hay tampoco monopolio de la justicia por parte del Estado, porque el Estado tiene un sistema judicial poco ágil, con la lentitud propia de las instituciones heredadas de la colonia. Este fenómeno (de pérdida del Estado como referente de justicia) se expresa en la percepción del ciudadano de que el ejercicio de la justicia obedece a retaliación, venganza o clientelismo antes que a principios de regulación democrática de las relaciones sociales. Esto, más la impunidad, permiten que cada día cobre más fuerza la justicia privada por parte de carteles de la droga (ajustes de cuentas), de paramilitares (dentro de la lógica contrainsurgente), de la insurgencia (control social de sus zonas a nombre de la justicia revolucionaria) y hasta la población civil (riñas callejeras, violencia social, etc.), prácticas donde los actores armados repiten las mismas prácticas que dicen combatir y que justifican su razón de ser (lucha contra la injusticia social, por la libertad de las personas, contra el chantaje y el secuestro, etc.).

En Colombia hay múltiples Estados (y tal vez el Estado central es el más débil y deslegitimado), estados-insurgencia, estados-delincuencia, estados-paramilitares, legitimados por la sociedad bajo su control gracias a que reproducen las mismas formas de relación burocráticas y clientelares aprendidas del Estado central. Estos para-estados no sólo tienen sus propios ejércitos sino que cobran impuestos y controlan el tránsito de la población (algunos grupos han desarrollado formas de prestación de servicio militar en sus propias filas). La división de facto del país es de tal nivel, que varios tratadistas internacionales hablan de la "balcanización" de Colombia y hasta proyectan la inminente división territorial de Colombia en varios años. Los actuales gobernadores y alcaldes hablan del "gobierno" como un ente ajeno a ellos, aunque ellos son "el gobierno" del orden departamental y municipal; igual expresión es usada incluso por ministros y generales.

Sin Estado (o con muchos) y sin paradigmas, en Colombia pasan cosas graves pero no cosas serias, no hay espacios de reflexión colectiva que le den, por ejemplo, a las masacres la magnitud de agresión al colectivo, precisamente, porque no existe proyecto colectivo.

Pero las partes de esa Colombia, o esas Colombias, generan tal impacto en otros países que su imagen es cada vez más trágica, el conocimiento de nuestra crisis en el exterior es casi nulo; la "exportación" de la violencia ha hecho que Panamá, Venezuela, Ecuador y Perú militaricen sus fronteras, y frente a Europa y Estados Unidos se mantiene como un país violento, impune y narcotraficante. Como dice el profesor Tokatlian, Colombia es un problema para el mundo.

Mientras todo esto sucede, la población colombiana, embebida en un pensamiento mágico, invoca fórmulas milagrosas y espontáneas de solución, como la intervención militar extranjera o la guerra frontal. Esta mentalidad busca salidas por fuera y por encima de la misma población, esperando a Ulises que regrese. Esa población no está formada por ciudadanos sino por castas, no está formada por personas sino por intereses individuales que, en su dinámica, reducen los derechos a privilegios conseguibles en relaciones clientelares para con el Estado y para con los otros. Una sociedad que perpetúa la impunidad y valida los círculos de poder como formas legales y normales de regular la vida social. Una sociedad que posibilita el crecimiento de personas como Pablo Escobar y le da entierro con honores. Una sociedad que usa, ante cada masacre, dos frases comunes: "por algo será " y "alguna cosa debía”, frases con las que se "justifican las masacres". Una sociedad que explica cada suceso violento como un caso aislado para no asumir que está autoaniquilándose, es una sociedad enferma. Una sociedad cómplice, sin nación ni Estado, sin proyecto colectivo.

\section{BIBLIOGRAFÍA}

AlCÁNTARA, Manuel (Ed.) (1996): América Latina: realidades y perspectivas. Memorias del Primer Congreso Europeo de latinoamericanistas. Salamanca: Ediciones Universidad de Salamanca.

Aministía Internacional (1994): Violencia Politica en Colombia: Mito y realidad. Madrid: EDAI.

AMnistía InTERnACIONAL (1998): Crónicas del Terror y de la Dignidad. Informe 1997, Madrid: EDAI. 1998.

CASTAÑEDA, Jorge G. (1995): La utopia desarmada. Barcelona: Ariel.

Chomsky, Noam (9 de Junio de 1996): "Ante los Guardianes de la Libertad" Magazin Dominical, El Espectador, $\mathrm{N}^{\circ}$ 682, 4-7.

CineP y Justicia y Paz (1996): Panorama de derechos bumanos y violencia politica en Colombia: Noche y Niebla. Núm. 1, Bogotá.

COMISIÓN COLOMBIANA DE JuRISTAS (1996): Colombia, derechos bumanos y derecho bumanitario: 1995. Bogotá.

De CuRREA-Lugo, Víctor (1997): De la violencia y otras costumbres. Bogotá: Signos e Imágenes.

DEBRAY, Regis (1967): ¿Revolución en la revolución?. La Habana: Casa de la Américas.

DeFensoría Del PUeblo (1998): Derechos Humanos para vivir en paz Quinto Informe del Defensor del Pueblo al Congreso. Bogotá.

El ESPECTADOR (17 de Mayo de 1996): "Una muerte violenta cada 20,5 minutos”, Periódico El Espectador, $3 \mathrm{~A}$.

EL TIEMPO (14 de Julio de 1998): "Estadísticas generales del secuestro 19961998". El Tiempo.

EL TIEMPO (19 de Mayo de 1998): "Impunidad: La gente tiene hoy la palabra” El Tiempo, 6A.

Franco, Saúl (1997): "Violencia y Salud en Colombia”. Rev. Panam Salud Pública, 2, 93-101.

Guillén MaRTínez, Fernando (1979): El poder politico en Colombia. Bogotá: Punta de Lanza. Citado por: JARAMILlo VÉLEz (1998): Moralidad y Modernidad en Colombia. Escuela Superior de Administración Pública.

Hernández, Isidro (1996): "La Bonanza de la Guerra”, en Revista Cien dias vistos por Cinep, 8-34, 12. Citado por la Comisión Colombiana de Juristas (1996), en: Op. cit. Colombia, Derechos Humanos y Dere cho Humanitario, 55.

Human RightS WATCH / AmÉRICAS (1996): Las redes de asesinos de Colombia: Militares, paramilitares y Estados Unidos. New York.

HuMAN RigHTS WATCH / AMÉRICAS (1997): Informe Anual sobre la Situación de los Derechos Humanos en el Mundo.

JARAMILlo VÉLEZ, Rubén (1998): Moralidad y modernidad en Colombia Escuela Superior de Administración Pública.

Medina Gallego, Carlos (1992): "Paramilitares, autodefensas y narco terrorismo en Colombia. 1980-1990”. Cuadernos Africa - América Latina, 7, 73-85. Madrid.

MonCAdA AGUdELO, Luis Fernando (1996): "De la lucha armada revolu cionaria a esa cosa llamada sociedad civil. Experiencia de la reinser ción guerrillera en Colombia”, en: AlCÁNTARA, Manuel (Ed.) (1996) América Latina: realidades y perspectivas. Memorias del Primer Congreso Europeo de latinoamericanistas. Salamanca: Universidad de Salamanca. 
Organización de Naciones Unidas (9 de abril de 1996). Consejo Económico y Social. E/CN.4 1996/ NGO /44.

Pizarro LeÓN-Gómez, Eduardo (1989): "Los orígenes del movimiento armado comunista en Colombia: 1949-1966", en Análisis Politico, 7, 7-31. Bogotá.

PIZARRO LEÓN-GÓMEZ, Eduardo (1991): "Elementos para una sociología de la guerrilla en Colombia”, en Análisis Político, 12, 7-22. Bogotá. SubdiRECCIÓN DE SERVICIOS ForeNCES (Noviembre 1995): Boletín del Centro de Referencia Nacional sobre violencia.
SubdirecCión de SERVicios Forenses. Instituto NaCiOnal DE MediciNA LEGAL Y CIENCIAS FORENSES (1995): Reporte del comportamiento de lesiones fatales y no fatales de Colombia, 1994. Santa Fe de Bogotá. VAlENCIA Villa, Hernando (1993): La justicia de las armas. Una crítica normativa de la guerra metodológica en Colombia. Bogotá: Tercer Mundo.

Waldmann, Peter (1995): "Represión estatal y paraestatal en Latinoamérica”, en América Latina Hoy, 10, 21-28. Madrid. Salamanca.

WETTSEIN, Germán (1991): "Los impunes, una minoría peligrosa”, en Nueva Sociedad, 111, 158-167. Caracas.

\section{RESUMEN}

"La desintegración nacional no es posible porque el país nunca ha estado articulado". Bajo esta premisa, el autor ensaya una reflexión sobre las múltiples dificultades de articulación que pesan sobre las relaciones que mantienen Estado y sociedad en Colombia. Realiza un repaso de las posiciones mantenidas por las diferentes fuerzas en conflicto -guerrillas, paramilitares, narcos, Ejército, Estados Unidos por medio de sus agencias-, que le lleva a concluir que la violencia armada generalizada e impune está conformando una sociedad cada vez más incapacitada para generar un proyecto colectivo.

Palabras clave: Colombia, Nación, violencia armada, desarticulación regional, proyecto colectivo

\section{ABSTRACT}

"The national desintegration is not possible because the country has never been articulated". Under this statement, the author reflects on the multiple difficulties of articulation between the State and the society in the colombian case. He makes a review of the positions standing by the different forces in conflict -guerrillas, paramilitaries, narcos, Army, USA through its agencies- which allows him to conclude that the generalized and unpunished armed violence is conforming a increasingly unable society to create a colective project.

Key words: Colombia, Nation, Armed Violence, Regional Disarticulation, Collective Project.

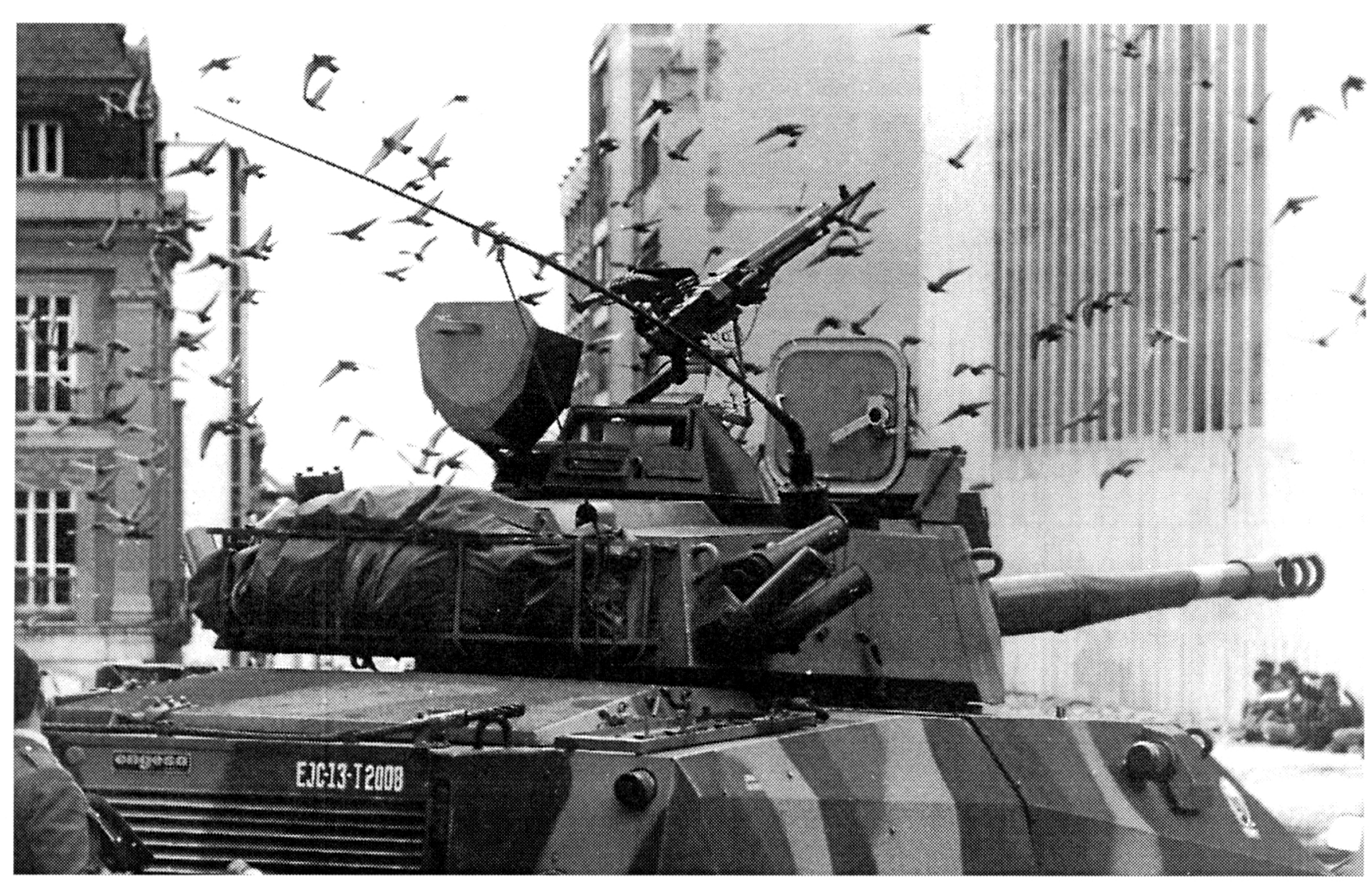

Gentileza de Fabiola Calvo. Toma del Palacio de Justicia, noviembre 1985 


\section{FORO INTERNACIONAL}

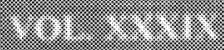

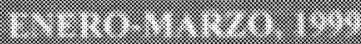

: $:$ : $:$ : $:$ : $:$ :

-

\section{EL COLECIO DE MEXICO}

